\title{
Transverse Beam Motion on the Second Axis of the Dual Axis Radiographic Hydrodynamic Test Facility
}

\author{
Y.-J. Chen \\ G. J. Caporaso \\ A. C. Paul \\ W. M. Fawley
}

This paper was prepared for submittal to the

1999 Particle Accelerator Conference

New York City, New York

March 29 - April 2, 1999

March 23, 1999

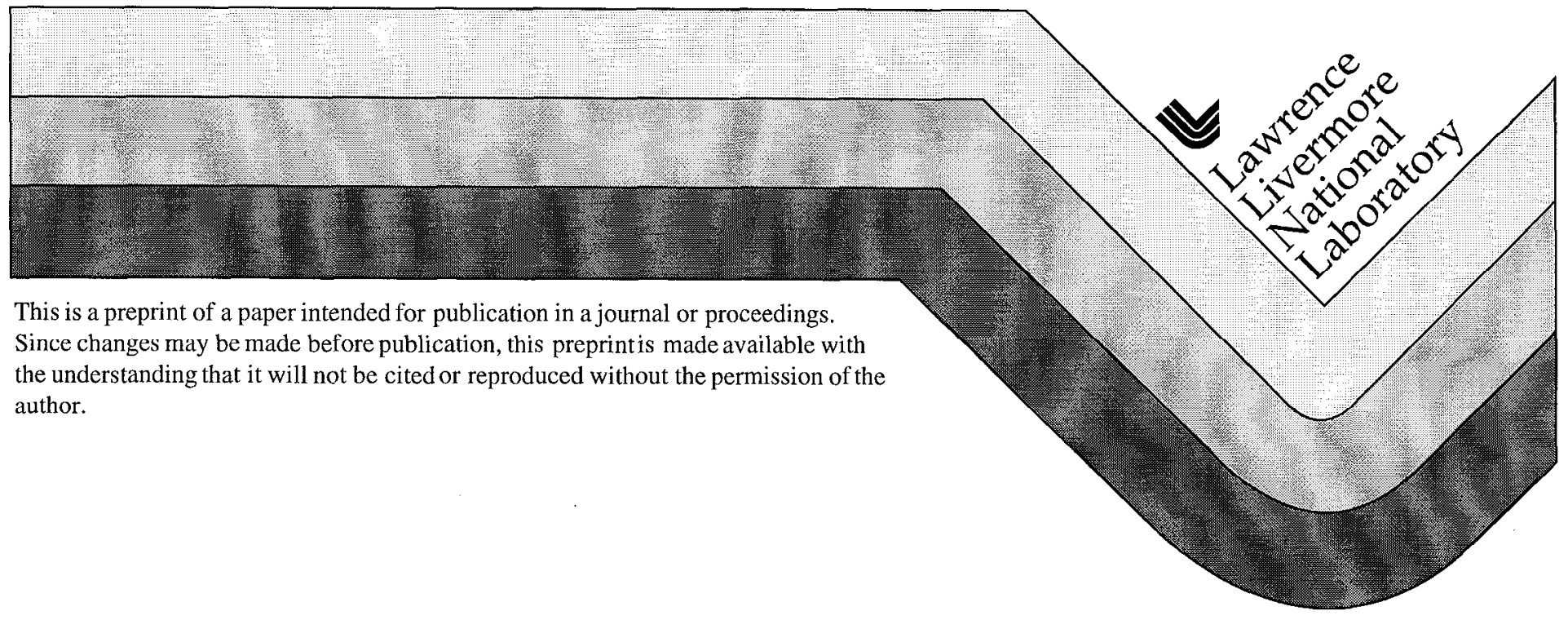




\section{DISCLAIMER}

This document was prepared as an account of work sponsored by an agency of the United States Government. Neither the United States Government nor the University of California nor any of their employees, makes any warranty, express or implied, or assumes any legal liability or responsibility for the accuracy, completeness, or usefulness of any information, apparatus, product, or process disclosed, or represents that its use would not infringe privately owned rights. Reference herein to any specific commercial product, process, or service by trade name, trademark, manufacturer, or otherwise, does not necessarily constitute or imply its endorsement, recommendation, or favoring by the United States Government or the University of California. The views and opinions of authors expressed herein do not necessarily state or reflect those of the United States Government or the University of California, and shall not be used for advertising or product endorsement purposes. 


\title{
TRANSVERSE BEAM MOTION ON THE SECOND AXIS OF THE DUAL AXIS RADIOGRAPHIC HYDRODYNAMIC TEST FACILITY*
}

\author{
Yu-Jiuan Chen ${ }^{+}$, George J. Caporaso, Arthur C. Paul, LLNL, Livermore, CA \\ William M. Fawley, LBNL, Berkeley, CA
}

\begin{abstract}
The accelerator on the second-axis of the Dual-Axis Radiographic Hydrodynamic Test (DARHT-II) facility [1] will generate a $20 \mathrm{MeV}, 2-4 \mathrm{kA}, 2 \mu \mathrm{s}$ long electron beam with an energy variation $\leq \pm 0.5 \%$. Four short current pulses with various lengths will be selected out of this $2 \mu$ s long current pulse and delivered to an $x$-ray converter target. The DARHT-II radiographic resolution requires these electron pulses to be focused to sub-millimeter spots on Bremsstrahlung targets with peak-to-peak transverse beam motion less than a few hundred microns. We have modeled the transverse beam motion, including the beam breakup instability, corkscrew motion [2, 3], transverse resistive wall instability [4] and beam induced transverse deflection in the kicker system, from the DARHT-I injector exit to the $\mathrm{x}$-ray converter target. Simulations show that the transverse motion at the $\mathrm{x}$-ray converters satisfies the DARHT-II radiographic requirements.
\end{abstract}

\section{INTRODUCTION}

To identify the test object's edges precisely, the DARHT$\Pi$ beam needs to be focused to a sub-millimeter spot on the $\mathrm{x}$-ray converter through its entire pulse. Transverse bean motion, which increases the time integrated spot size, is one of principle limitations in achieving the spot size requirement. The main sources of transverse motion in the accelerator are injector noise, misalignments and energy variations. These sources lead to the beam breakup instability (BBU) and corkscrew motion. The leading sources in the downstream beamline are beam induced transverse deflection in the kicker system and the head and tail of beam motion due to the switching of the kicker pulser. The DARHT-II accelerator will deliver a $2 \mu \mathrm{s}$ long, 2-4 kA electron beam. The long duration and the high current make the transverse resistive wall instability a possible concern for the transverse beam motion.

We have modeled the transverse motion of a $2-4 \mathrm{kA}$ beam from the exit of the DARHT-II injector to the $\mathrm{x}$-ray converter to ensure that the DARHT-II facility meets design goals. The DARHT-II injector delivers a $400 \mathrm{~ns}$ rise time current pulse, and the accelerator gap voltage has a $200 \mathrm{~ns}$ rise time. There are concerns that the $400 \mathrm{~ns}$ long beam head would be lost in the accelerator and cause gas desorption from the wall. A beam head cleanup zone after the first 8-cell block is being proposed. Various accelerator configurations without the beam head cleanup zone are simulated. However, the current rise time sharpener effect of the beam head cleanup is included.

\footnotetext{
* The work was performed under the auspices of the U.S. Department of Energy by LLNL under contract W-7405-ENG-48, and by LBNL under contract AC03-76SF00098

tEmail: yjchen@llnl.gov
}

Three simulation codes are used for the modeling: BREAKUP for transport in the accelerator, TRANSPORT to determine transformation matrices of the downstream beamline components, and KICKER to transport the BREAKUP outputs to the $\mathrm{x}$-ray converter through a kicker system. Section 2 shows that corkscrew motion can be controlled by using the corkscrew tuning $\mathrm{V}$ algorithm, and the BBU and the rise time sharpener effect of the cleanup zone do not change the DARHT-II performance. We will discuss the transverse resistive wall instability in Section 3. In section 4, we will present our modeling of the transverse beam motion in the kicker system and the final beam motion at the converter target. A summary will be given in Section 5 .

\section{BEAM MOTION IN THE ACCELERATOR}

\subsection{Accelerator Configuration and Cell Impedance}

The DARHT-II accelerator consists of eleven 8-cell blocks $[1,5]$. Three cell configurations, which differ in the insulator geometry and bore size, have been designed [6]. Four cell combinations were used in the simulations: 88 initial cells, 88 standard cells, 8 injector cells with 80 standard cells, and again 8 injector cells with 80 standard cells. Except the fourth one, all combinations have one intercell magnet within each intercell. All the solenoids are wrapped with steering/correction coils. The magnetic tune focuses the $8 \mathrm{~cm}$ radius electron beam at the injector exit rapidly to a $5 \mathrm{~mm}-1 \mathrm{~cm}$ radius without adversely affecting the current distribution and losing beam head in the first block. The small beam radius is then maintained through the rest of the accelerator. The pertinent cell charactcristics for BBU calculations are listed in Table 1. For the configurations consisting of 8 injector cells and 80 standard cells, only three dominant modes $(171 \mathrm{MHz}$, $200 \mathrm{MHz}$ and $635 \mathrm{MHz}$ ) are modeled in the simulations. We expect the simulation results with the discrete, dominant modes to be similar to that with a continuous BBU spectrum [7].

Table 1: Impedances of different cell configurations

\begin{tabular}{|c|c|c|c|}
\hline Design & Freq. $(\mathrm{MHz})$ & $\mathrm{Z} / \mathrm{Q}(\Omega)$ & $\mathrm{Q}$ \\
\hline Initial Cell & 262 & 34.9 & 2.0 \\
\cline { 2 - 4 }$(25.4 \mathrm{~cm}$ ID) & 580 & 1.1 & 7.2 \\
\cline { 2 - 4 } & 672 & 3.9 & 6.9 \\
\hline $\begin{array}{c}\text { Standard Cell } \\
(25.4 \mathrm{~cm} \text { ID) }\end{array}$ & 200 & 37.57 & 1.9 \\
\cline { 2 - 4 } & 635 & 7.28 & 3.8 \\
\hline $\begin{array}{c}\text { Injector Cell } \\
(35.6 \mathrm{~cm} \text { ID) }\end{array}$ & 171 & 25.41 & 2.0 \\
\cline { 2 - 4 } & 443 & 4.3 & 4.2 \\
\hline
\end{tabular}




\subsection{Beam Breakup Instability}

The convective BBU instability arises from the beam interacting with the accelerating cells' dipole TM modes. For a current pulse with a long rise time, the BBU instability driven by the shock cxcitation of misalignment starts to grow at the beam head and may not propagate into the main body of the pulse before the beam leaves the accelerator. Therefore, the BBU instability driven by misalignment is generally not a threat to a long rise time DARHT-II pulse. However, to minimize the beam head loss to the wall, the head cleanup zone between the first two blocks sharpens the current rise time to $50 \mathrm{~ns}$ with or without a current precursor depend on the cleanup zone's configuration [8]. The fourth accelerator configuration is used to model the beam head cleanup's current rise time sharpening effect on BBU. Two cases are studicd. In the first case, the current pulse's rise time is $45 \mathrm{~ns}$ through the entire accelerator. In the second case, the current pulse has a $140 \mathrm{~ns}$ rise time initially and is shortened to $45 \mathrm{~ns}$ between the first two blocks (the potential cleanup zone), and a $800 \mathrm{~A}$ current precursor is added at $50 \mathrm{~ns}$ before the head of the current flattop. A injector noise is also included in the simulations since the BBU driven by injector noise would appear throughout the pulse length and causes concerns.

\subsection{Corkscrew and Tuning Strategy}

Corkscrew motion driven by the focusing elements' chromatic aberration and the machine's misalignment is a differential oscillation of the beam centroid between the leading and trailing portions of a beam pulse. The simulations use the DARHT-I accelerator's alignment specification: $1.95 \mathrm{mrad}$ of random $3-\sigma$ magnetic tilt and $0.45 \mathrm{~mm}$ of random $3-\sigma$ magnet offset. Without corrective measures, this specification would produce a corkscrew amplitude of several millimeters at the accelerator exit. The simulated beam pulse has an energy variation of $\pm 0.5 \%$. Large injector offset $(\sim 1 \mathrm{~mm})$ and tilt $(\sim 1 \mathrm{mrad})$ introduced by the dipole field in the DARHT-II injector configuration is also modeled. Let $R$ be the averaged centroid radial displacement over the flattop portion of the current pulse, and $A$ be the averaged corkscrew amplitude. The tuning- $V$ steering algorithm, which has demonstrated an order of magnitude reduction in corkscrew on the ETAII accelerator [3,9] and the Flash X-ray Radiography accelerator (FXR) [10], is used to minimize a figure of merit $W$, where $W=R^{2}+A^{2}$. The available steering field for each steering coil is limited to 5 Gauss in the simulations, and only 1-4 pairs of steering coils per beam position monitor (BPM) are used to steer the beam.

\subsection{BREAKUP Results}

Several observations can be made from the simulations. First, the beam head electrons with energy less than 10 $\mathrm{MeV}$ are lost early in the accelerator due to large corkscrew motion and BBU. At the accelerator exit, the $\mathrm{BBU}$ on a $2 \mathrm{kA}$ beam body is insignificant compared with the corkscrew amplitude even if there is a $170-200 \mathrm{MHz}$, $100 \mu \mathrm{m}$ injector noise imposed on the initial beam centroid as shown in Figs. 1(a), (b) and (c). A similar observation can be made for a $4 \mathrm{kA}$ with a $10 \mathrm{~mm}$ injector noisc. For a $2 \mathrm{kA}$ bcam with $45 \mathrm{~ns}$ rise time, the projected beam centroid on the $x-y$ plane for the flattop portion of a beam (a) without and (b, c) with steering are presented in Fig. 1. Figures 1(b) and (c) show that the corkscrew amplitudes are $\sim 0.3 \mathrm{~mm}$ with the tuning-V steering regardless whether there is a current precursor. The BBU caused by the shock excitation of misalignment extends only a short distance into the flattop of a $4 \mathrm{kA}$ pulse and does not appear in the flattop of a $2 \mathrm{kA}$ pulse for both current rise time sharpening cases. The tuning-V steering reduces the corkscrew amplitude by an order of magnitude even though a large injector offset and tilt are present. Though the steering reduces the beam offset at the BPM by making the beam centroid cross the axis, the reduction of the beam displacement between the BPMS is less than a factor of two. Hence, the BBU amplitude stays almost unchanged regardless of steering. The average beam offset in the accelerator is about $2-3 \mathrm{~mm}$ which is much less than beam pipe radius. Emittance growth due to the nonlinear image forces is expected to be small.
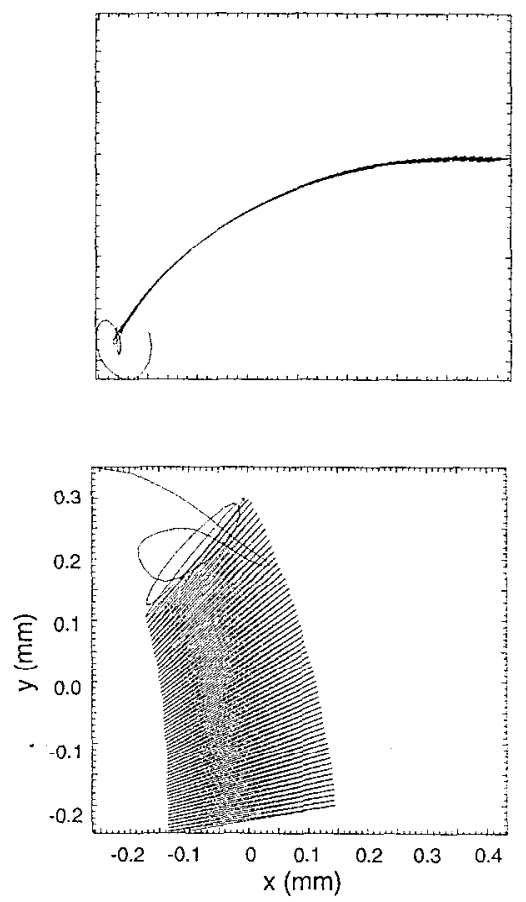

Fig. 1 The projected beam centroids on the $x-y$ plane for the flattop portion of a $2 \mathrm{kA}$ beam shows corkscrew amplitude is (a) $\sim 2 \mathrm{~mm}$ without steering and $(b, c) \sim 0.3 \mathrm{~mm}$ with the tuning- $\mathrm{V}$ steering. 


\section{TRANSVERSE RESISTIVE WALL INSTABILITY}

The transverse resistive wall instability arises from the head-to-tail growth of the non-cancellation forces of the surface charges and the surface currents created by an offset beam in the conducting pipe. Providing a continuous focusing channel with a large pipe aperture is an effective way to minimize the instability growth. Generally, the instability growth for a few hundred nanosccond long beam is insignificant. The transverse resistive wall instability may be a concern for the $2 \mu$ s long, 2-4 kA beam while it travels in the drift regions between the injector and the kicker septum. However, we find that the instability is not an issue in the proposed beam head cleanup zone ( a $2 \mathrm{~m}$ drift space) with a $25.4 \mathrm{~cm}$ diameter stainless steel pipe since the characteristic growth length is $6.4 \mathrm{~m}$ for a $2 \mathrm{kA}$ beam and $4.5 \mathrm{~m}$ for a $4 \mathrm{kA}$. In the downstream (with two $\sim 3 \mathrm{~m}$ long drift regions) with a 16 $\mathrm{cm}$ diameter stainless steel pipe, the characteristic growth length is also $6.4 \mathrm{~m}$ for a $2 \mathrm{kA}$ beam and $4.5 \mathrm{~m}$ for a 4 $\mathrm{kA}$. We have included the transverse resistive wall instability in the modeling (see the next section).

\section{BEAM MOTION IN DOWNSTREAM TRANSPORT LINE}

The transverse centroid is modeled by using the system simulation code Extend. The centroid motion as a function of time at the accelerator exit as taken from BREAKUP is used as input into the Extend simulation. There is a detailed model of the kicker, its pulser system and transit time isolation cable system including dispersion due to skin effect. There is also a model of the quadrupole lens which acts as a septum magnet [11] and a model for the split beam pipe which treats the impedance of the pipe as due to a single high $Q$ mode. The transport from the accelerator output to the input of the kicker is computed by using a $6 \times 6$ matrix, obtained from the TRANSPORT code, for this section of beamline. Similarly, another matrix, extracted from the TRANSPORT code, is used to represent the transport line from the output of the septum pipe to the focal plane (on the target) of the final lens. The simulation incorporates a model of a rise time sharpening aperture at the output of the split beampipe. The beam profile is assumed to be a Gaussian and there is an aperture of radius $2 \mathrm{~cm}$. This aperture is able to sharpen up the risetime of the selected pulse.

A typical resultant centroid motion at the target and transmitted current are shown in figure 2. The current pulse selected by the kicker system has a 8 ns rise/fall time. The maximum beam displacement (occuring at the rising part of the pulse) within the FWHM is $\sim 0.35 \mathrm{~mm}$ which is about a half of the beam radius on the target. On the flattop portion of the beam, the displacement (the high frequency BBU oscillations) is less than $100 \mu \mathrm{m}$. If the pulse width is only $20 \mathrm{~ns}$, the averaged beam displacement weighted by the beam current is about $100 \mu \mathrm{m}$ which is reasonably small compared with the required beam radius, 0.65 mm FWHM.
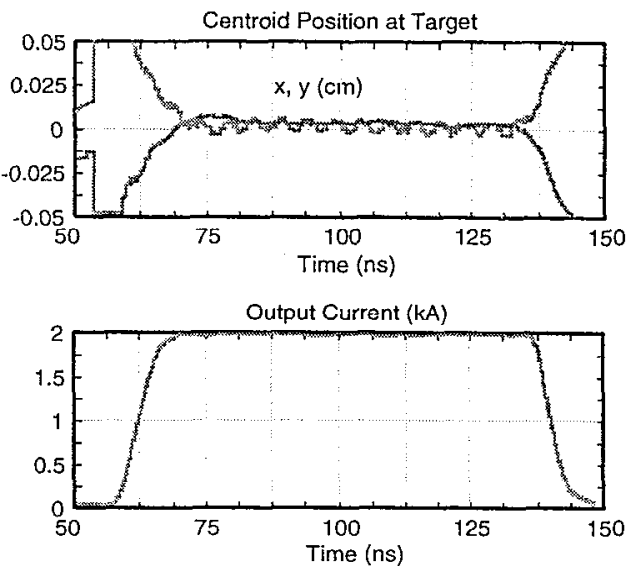

Fig 2. Extend simulation output showing the centroid motion on the x-ray target of a section selected out of the accelerator output pulse and the associated transmitted current arriving at the target.

\section{SUMMARY}

We have modeled the transverse motion of a $2-4 \mathrm{kA}$ beam from the exit of the DARHT-II injector to the $x$-ray converter. The simulation model includes the beam breakup instability, corkscrew motion, the transverse resistive wall instability, the kicker induced transverse kick, the head and tail's beam motion due to the switching of the kicker pulser. 'The model also includes the rise time sharpening effect of the beam head cleanup scheme and the small output aperture of the septum. Simulations show that the transverse motion on the $\mathrm{x}$-ray converter target should meet the DARHT-II radiographic requirements.

\section{REFERENCES}

[1] M. J. Bums, et al., "DARHT Accelerators Update and plans for Initial Operation", proceedings of this conference.

[2] Y.-J. Chen, "Corkscrew Modes in Linear Accelerators", Nucl Instr. and Meth. A 292 (1990) p.455-464.

[3] Y.-J. Chen, "Control of Transverse motion Caused by Chromatic Aberation and Misalignments in Linear Accelerators", Nucl. Instr. and Metl. A 398 (1997) p.139-146.

[4] G. J. Caporaso, W. A. Barletta, and V. K. Neil, "Transverse Resistive Wall Instability of a Relativistic Electron Beam", Particle Accel. (1980) pp.71-79.

[5] H. Rutkowski, et al., "A Long Pulse LINAC for the Second Phase of DARHT", proceedings of this conference.

[6] T. L. Houck, et al., "Physics Design of the DARHT 2nd Axis Accelerator Cell," proceedings of LINAC98, Chicago, 1998.

[7] W. M. Fawley, Y.-J. Chen and T. L. Houck, "Beam Breakup Calculations for the Second Axis of the DARHT", proceedings of this conference.

[8] T. Houghes and A. C. Paul, Private communications.

[9] J. Weir, et al., "Improved ETA-II Accelerator Performance", proceedings of this conference.

[10] R. Scarpetti, Private conversation.

[11] A. C. Paul, et al., "The Beamline for the Second Axis of the Dual Axis Radiographic Hydrodynamic Test Facility", proceedings of this conference. 